\title{
A Participação do Tecido Adiposo Visceral na Gênese da Hipertensão e Doença Cardiovascular Aterogênica. Um Conceito Emergente
}

\author{
Sergio Girão Barroso, Virgínia Genelhu de Abreu, Emílio Antonio Francischetti
}

Rio de Janeiro, RJ

O conceito de que o excesso de tecido adiposo visceral está associado às complicações metabólicas e hemodinâmicas envolvidas em mecanismos que levam à doença cardiovascular aterogênica e hipertensão arterial não é recente. Em 1947, Vague ${ }^{1}$ descrevia dois tipos de distribuição de gordura corporal: o andróide ou tipo masculino e o ginecóide exteriorizando características somáticas femininas. Quase 10 anos depois, o mesmo autor propõe que os diferentes tipos de obesidade se acompanhavam de riscos distintos de complicações, a obesidade andróide associandose com maior freqüência ao diabetes, gota e doença coronariana ${ }^{2}$. Nos anos subseqüentes, a idéia básica de Vague foi comprovada por numerosos estudos prospectivos ${ }^{3-5}$. Por outro lado, várias linhas de pesquisa têm mostrado o envolvimento do tecido adiposo na fisiopatologia da hipertensão arterial e suas complicações ${ }^{6-8}$.

Atualmente as células adiposas não são tidas apenas como estruturas de proteção e sustentação, mas como um verdadeiro órgão dotado de intensa atividade endócrina e metabólica ${ }^{9}$. A descoberta da leptina, por exemplo, deixou claro que o tecido adiposo participa ativamente do controle do dispêndio energético e do apetite, através de seus efeitos sobre o sistema nervoso simpático e função cardiovascular ${ }^{8}$.

A década de 90, porém, foi muito além da leptina quanto à caracterização de outras moléculas reguladoras da homeostase circulatória e energética expressas e secretadas pelos adipócitos. Mostrou que o inibidor do ativador de plasminogênio 1 (PAI-1) estava aumentado no sobrepeso e obesidade graças à maior expressão de seu RNAm no tecido adiposo ${ }^{10}$. Registrou que o angiotensinogênio tinha seus

Clínica de Hipertensão e Obesidade, Laboratório de Fisiopatologia Clínica e Experimental - Clinex e Faculdade de Ciências Médicas da UERJ

Correspondência: Emílio A. Francischetti - Rua Voluntários da Pátria, 329/603 22270-000 - Rio de Janeiro, RJ - E-mail: emilioaf@cardiol.br

Recebido para publicação em 6/4/01

Aceito em 8/8/01 níveis séricos elevados na obesidade devido à sua maior síntese pelos adipócitos, o que geraria mais angiotensina II e elevação da pressão arterial, seja pelos efeitos diretos do peptídeo sobre o rim, ou pela ativação simpática ${ }^{11}$. Também, constatou-se que a angiotensina dos adipócitos participava da regulação da neurotransmissão simpática envolvida no controle do metabolismo lipídico, regulando o volume dessas células, controlando as enzimas do metabolismo de ácidos graxos e agindo como agente modulador do peso corporal $^{12}$.

O tecido adiposo secreta citocinas atuantes em mecanismos responsáveis pela sensibilidade à insulina, como é o caso do fator de necrose tumoral alfa (TNF- $\alpha)^{13}$, e moléculas de sinalização, recentemente identificadas, como a resistina e a adipsina - proteína estimuladora da acilação (ASP, acylation stimulating protein $)^{14,15}$. Além disso, a homeostase adequada do tecido adiposo pressupõe a participação de moléculas de glicose e ácidos graxos desenvolvendo intensa atividade metabólica ${ }^{16}$.

Em países afluentes a obesidade e o sobrepeso afetam quase a metade da população adulta, sendo responsáveis por 8 a $10 \%$ dos custos totais despendidos com a saúde ${ }^{17}$. Em nações em desenvolvimento, como o Brasil, a situação não é muito diferente, observando-se aumento expressivo da prevalência de obesidade na últimas décadas ${ }^{18}$. A obesidade, particularmente a obesidade visceral, é um sério problema de saúde pública, fazendo parte da síndrome cardiovascular dismetabólica ou síndrome $\mathrm{X}$, que se caracteriza pela agregação de outros fatores de risco, que se associam fortemente a morbi-mortalidade cardiovascular ${ }^{19}$.

O objetivo da presente revisão é apresentar resultados de estudos que têm trazido mais luz às interassociações potenciais da regulação do metabolismo do tecido adiposo por proteínas, hormônios e peptídeos, muitos recentemente caracterizados no próprio tecido, com vista a entender melhor os mecanismos que levam ao aparecimento das complicações cardiovasculares e da hipertensão em indivíduos com excesso de adiposidade visceral. 


\section{Leptina, proteína lipostática com ações hemodinâmicas}

Há muitos anos já se reconhecia que o fenótipo da obesidade se expressava pelo menos em quatro mutações de roedores: nos camundongos obesos (ob/ob), nos camundongos diabéticos $(d b / d b)$, e em ratos geneticamente obesos: os agouti e os Zuker ou $\mathrm{fa} / \mathrm{fa}{ }^{20}$. Os estudos clássicos de parabiose sugeriam que um fator circulante seria secretado em resposta ao aumento das reservas adiposas ${ }^{21}$ Coleman e cols. ${ }^{20}$ admitiam que os camundongos $o b / o b$ não produziam este fator e que camundongos $d b / d b$, embora o tivessem, não respondiam ao mesmo. Outros trabalhos apontavam haver uma falha na resposta a este fator em ratos $f a / f a$, à semelhança do que ocorre em animais $d b / d b^{22}$, e resposta inadequada ao mesmo em ratos agouti ${ }^{23}$.

A descoberta do gene $o b$ em 1994, e a clonagem de seu produto genético, a leptina, pelo grupo de Friedman, da Rockefeller University, abriram as portas da pesquisa deste peptídeo produzido pelas células adiposas ${ }^{24}$. Em camundongos $o b / o b$, a mutação genética é acompanhada de ausência de síntese de leptina, resultando em obesidade mórbida $^{24}$. Entre outras ações, a leptina ativa receptores hipotalâmicos, inibindo a secreção de neuropetídeo Y (NPY), diminuindo o apetite e aumentando a termogênese pela ativação do sistema nervoso simpático ${ }^{25,26}$.

A leptina é um hormônio peptídico de $16 \mathrm{kd}$, secretado principalmente pelo tecido adiposo e, em escala menor, pela medula óssea, placenta, estômago e tecido hipotalâmico ${ }^{27,28}$. As concentrações de leptina são proporcionais ao volume de células adiposas e aumentam em proporção à elevação do percentual de gordura corporal ${ }^{29}$. Esquematicamente, uma alça de retroalimentação negativa, regulada pela leptina, originada e controlada pelo próprio tecido adiposo, atuaria em centros hipotalâmicos, para controlar o apetite, a termogênese e o peso corporal ${ }^{30-32}$ (fig. 1).

Existem duas isoformas principais do receptor de leptina humana, a forma curta e a forma longa, e são expressas no hipotálamo, núcleo arqueado, plexo coróide e leptomeninges ${ }^{33,34}$. O tamanho do adipócito parece ser o principal determinante da quantidade de RNAm do gene $o b$, as células maiores expressando mais leptina do que as células menores isoladas de um mesmo indivíduo. Além do tamanho das células adiposas, vários hormônios e agentes farmacológicos regulam a produção de leptina ${ }^{35}$. Glicocorticóides estimulam a produção de leptina ${ }^{36}$. Agonistas betaadrenérgicos agem de forma distinta ${ }^{35}$. Por outro lado, a síntese de leptina é estimulada também por citocinas, como a interleucina $1 \alpha$ e o fator de necrose tumoral ${ }^{37,38}$, além de estrógenos ${ }^{39}$.

Os níveis de leptina estão aumentados na maior parte dos indivíduos obesos ${ }^{40}$. Isto levanta a hipótese de resistência a ação da leptina, como a que ocorre em camundongos diabéticos $d b / d b^{41}$, cuja expressão do fenótipo é semelhante ao encontrado no polimorfismo do gene $o b$, porém com concentrações séricas altas de leptina.

\section{Outras vias de sinalização da leptina: melano- cortina e proteína agouti}

O gene agouti do rato obeso amarelo $\left(A^{y} a\right)$ foi o primeiro gene associado à obesidade a ser identificado em roedores ${ }^{42,43}$. Graças a isso, foi demonstrado que a proteína agouti (AGRP, agouti related protein) inibiria a ação de um neuropetídeo, o hormônio estimulante da melanocortina $(\alpha M S H)$, sobre seus receptores do tipo 4 (MC4R, melanocortin receptor 4). Como esses receptores são expressos no hipotálamo e em outras regiões que regulam funções neuroendócrinas, tem-se especulado que os efeitos do gene $A^{y} a$ sobre os mesmos poderiam ter importante papel no desenvolvimento da obesidade ${ }^{44}$. A proteína agouti exerce o papel de molécula anabolizante, causando hiperfagia quando administrada no interior de ventrículos cerebrais ${ }^{45}$. Embora o NPY tenha sido descrito como molécula orexígena, seus efeitos são atuantes, apenas a curto prazo, quando comparados aos das proteínas agouti. A proteína agouti é atualmente considerada como a molécula estimuladora do apetite mais robusta em termos de potência e duração de ação ${ }^{46}$.

As melanocortinas são peptídeos obtidos do processamento das pro-opiomelanocortinas $(P O M C)$, cuja expressão gênica é limitada quase que exclusivamente ao hipotála$\mathrm{mo}^{47}$. A $\alpha$-melanocortina é regulada pela ingestão alimentar, em parte pela ativação de neurônios que expressam o $R N A m$ das proopiomelanocortinas modulado pela leptina ${ }^{48}$. Havendo depósito de gordura abundante, os níveis circulantes de leptina estão aumentados e ativam receptores residentes no núcleo arqueado do hipotálamo, que possuem neurônios produtores de proopiomelanocortinas. A função última da leptina seria estimular a expressão e liberação de $\alpha$-melanocortinas, via proopiomelanocortinas, aumentando assim a síntese de $A M P c$ de células que contêm receptores de $\alpha$-melanocortinas. Tem-se postulado que os neurônios que contêm receptores de $\alpha$-melanocortinas inibem neurônios do hipotálamo lateral, cuja função é estimular o apetite ${ }^{49}$ (fig. 1). Agonistas sintéticos desses receptores suprimem a ingestão de alimentos, enquanto antagonistas tem efeito oposto ${ }^{50}$. Camundongos que não expressam esses receptores são hiperfágicos e extremamente obesos ${ }^{51}$ indicando que a sinalização tônica desses receptores limita a ingestão calórica e a massa adiposa corporal.

Recentemente, foram descritos outros peptídeos sintetizados por neurônios para-ventriculares e envolvidos na homeostase energética, associados às concentrações séricas de leptina: o fator liberador de corticotropina (CRH, corticotropin- releasing hormone) e o hormônio liberador de tirotropina (TRH, thyrotropin releasing hormone) ${ }^{52}$. Este último, através de estímulo do sistema de $\alpha$-melanocortinas, aumenta a liberação de TSH, elevando as concentrações dos hormônios tireoidianos ${ }^{53}$.

\section{Tecido adiposo e sistema renina-angiotensina}

A célula adiposa é uma das poucas células que dispõem não só de todo o maquinário e ferramentas necessári- 


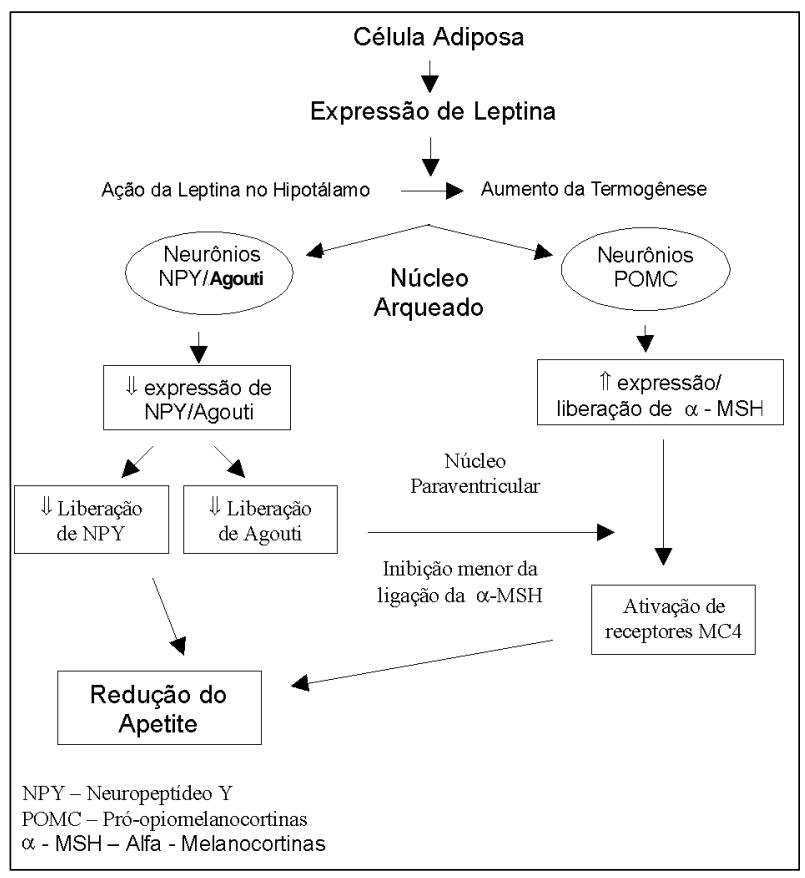

Fig. 1 - Vias de sinalização da leptina e ações sobre o apetite e gasto energético.

os para a síntese de angiotensina II como aloja em sua membrana a sub-unidade $\mathrm{AT}_{1}$ de seu receptor, modulador de boa parte de suas respostas ${ }^{54}$. Os níveis de RNAm de angiotensinogênio são $60 \%$ maiores no tecido adiposo do que no fígado, considerado até então a principal fonte do substrato da renina ${ }^{55}$. Tem-se demonstrado que a expressão de RNAm do angiotensinogênio é regulado por ácidos graxos livres ${ }^{56}$ e que os glicorticóides aumentam ${ }^{57}$ e a insulina diminui essa expressão ${ }^{58}$.

Estudos recentes mostraram que o tecido adiposo interescapular processa toda a atividade enzimática do sistema renina-angiotensina, inclusive as vias alternativas ${ }^{59}$. Embora essa característica não seja uniforme entre as espécies, o tecido adiposo humano expressa vários componentes do sistema, inferindo-se daí que sua contribuição na modulação da homeostase circulatória pode ser importante ${ }^{60}$.

Os sítios de afinidade entre o receptor $\mathrm{AT}_{1} \mathrm{e}$ a angiotensina II têm cinética semelhante aos de outros órgãos alvos do peptídeo sendo a densidade desse receptor no tecido adiposo semelhante a do coração ${ }^{54}$. Curiosamente, em que pese as células adiposas isoladas do tecido adiposo humano demonstrarem apenas a presença de receptores $\mathrm{AT}_{1}$, muitas das ações da angiotensina são antagonizadas por agentes que bloqueiam a atividade de receptores $\mathrm{AT}_{2}$ em células adiposas em cultura ${ }^{61}$.

Entre as funções da angiotensina II do tecido adiposo a liberação de norepinefrina pelo SNS parece ser a mais evidente. Pesquisas realizadas por Lisa Cassis ${ }^{62}$ apontaram que a angiotensina II teria um papel potencial significativo na termogênese induzida pelo frio do tecido adiposo marrom. Além disso, ratos obesos fa/fa mostram reduzida atividade da renina plasmática e menor densidade dos receptores $\mathrm{AT}_{1}$ no tecido adiposo, que se associam a modesta res- posta do peptídeo quanto a liberação de norepinefrina, quando comparados aos animais controle ${ }^{63}$. A infusão crônica de angiotensina II se acompanha de importante redução no peso e na ingestão de alimentos, possivelmente pela maior liberação de norepinefrina, o que contribuiria para o aumento da atividade metabólica e elevação do dispêndio energético ${ }^{64}$. É possível que os estados de caquexia extrema, freqüentemente presentes nos estágios terminais da insuficiência cardíaca crônica, possam ser explicados pelos níveis aumentados de angiotensina II, invariavelmente presentes nesta fase da disfunção ventricular.

Estudos utilizando cultura de células adiposas mostraram que $\mathrm{o}$ angiotensinogênio e a angiotensina II participam da regulação e diferenciação do fenótipo do adipócito ${ }^{64}$. É provável que o aumento no conteúdo de triglicerídeos e da atividade de duas enzimas lipolíticas, a sintetase de ácidos graxos e a glicerol-3-fosfato desidrogenase, sejam mediadas pela angiotensina II, mostrando que o peptídeo controla a adiposidade pela regulação da síntese e armazenamento de lipídeos ${ }^{65}$ (fig. 2). Apesar dessas discrepâncias aparentes, as implicações da angiotensina na gênese da hipertensão do obeso começam a se tornar cada vez mais óbvias: em cultura de células adiposas, a angiotensina II é fator adipogênico enquanto no animal vivo, atua como importante redutor do peso e da massa adiposa.

Resultados de pesquisa recente, em que se avaliaram as relações entre angiotensinogênio, leptina e níveis de pressão arterial em um grupo de jovens normotensos, evidenciaram que o substrato da renina se correlacionou significativamente com o índice de massa corporal, níveis plasmáticos de leptina e pressão arterial, nos indivíduos

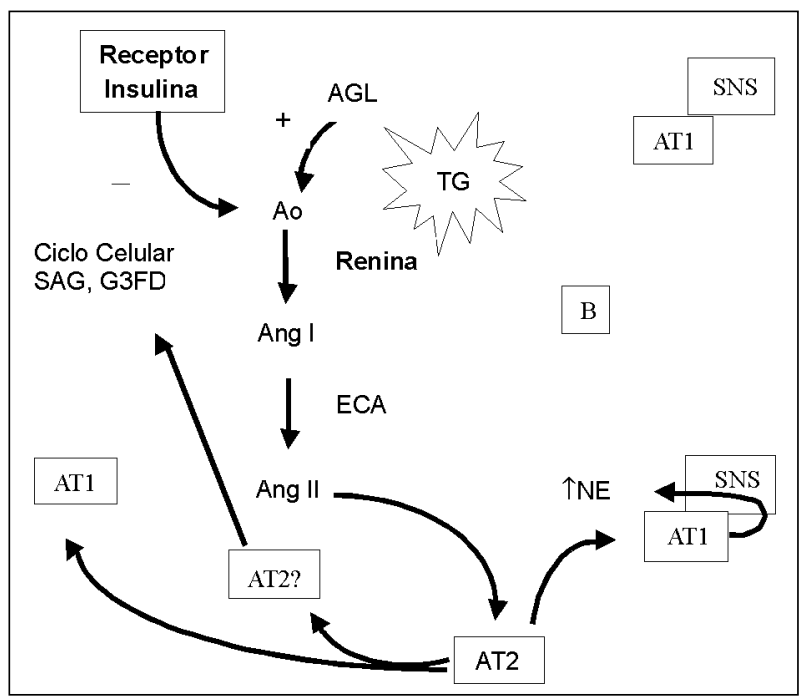

Fig. 2 - $\mathrm{O}$ sistema renina-angiotensina do tecido adiposo. $\mathrm{O}$ angiotensinogênio (Ao) é sintetizado nos adipócitos e processado pela renina e ECA a angiotensina I (Ang I) e angiotensina II (Ang II). Receptores At1 e possivelmente AT2 são expressos nos adipócitos atuando no ciclo celular e na síntese de enzimas da lipogênese. A insulina e os ácidos graxos livres (AGL) modulam a produção de Ao pelos adipócitos. As funções de Ang II incluem a ativação do SNS, aumentado da atividade do receptor b-adrenérgico (B), controle da lipólise e estímulo ao metabolismo da célula adiposa. ECA- enzima de conversão de angiotensina; SAG- sintetase de ácidos graxos; G3FD glicerol-3 - fosfato desidrogenase; NE- norepinefrina; TGtriglicérides; SNS- sistema nervoso simpático. Adaptado de Lisa Cassis ${ }^{69}$. 
com história familiar positiva para hipertensão arterial. Concluiu-se que os níveis circulantes de angiotensinogênio contribuíram para a relação entre peso corporal e pressão arterial ${ }^{66}$. Outro fator intrigante é a capacidade relativamente maior do tecido adiposo visceral em secretar os componentes do SRA. Isto poderia ser um fator a mais para justificar o maior risco cardiovascular associado à distribuição central da gordura ${ }^{67}$. Por outro lado, é possível que o menor risco de doença cardiovascular em mulheres se justifique, em parte, pela menor atividade do SRA de origem adiposa, quando comparada ao de homens ${ }^{68}$. Embora sejam resultados preliminares, é muito provável que a angiotensina II derivada do tecido adiposo exerça um papel chave na modulação do metabolismo lipídico e atue também como elo de ligação entre obesidade e hipertensão ${ }^{69}$. Além disso, a hipótese de que uma maior expressão do gene do angiotensinogênio em obesos contribua para os mecanismos perpetuantes do excesso de peso é bastante atraente, necessitando de pesquisas clínicas e experimentais adicionais.

\section{Outros mediadores secretados pelo tecido adiposo: adipsina, fator de necrose tumoral- alfa e resistina}

A proteína estimuladora de acilação foi descoberta em 1990 quando imunologistas estudavam as etapas de produção da adipsina pelos adipócitos. Essas células sintetizam e secretam três proteínas do sistema complemento: o terceiro componente (C3), o fator B, e o fator D ou adipsina ${ }^{14}$. A interação dessas três proteínas resulta na adipsina, que nos adipócitos alteia a atividade da proteína quinase $\mathrm{C}$, promovendo não só o transporte de glicose como a reesterificação de ácidos graxos originados da lipólise, resultando em maior síntese de triglicerídeos em um dos ciclos fúteis mais importantes do organismo ${ }^{15}$. Em altas concentrações, mas dentro da faixa fisiológica, a adipsina, diminui a liberação de ácidos graxos, efeito que é potencializado pela insulina ${ }^{14}$. Polimorfismos da adipsina já foram descritos em obesos, parecendo contribuir para a hipertrigliceridemia freqüentemente encontrada nesses pacientes ${ }^{15}$.

OTNF- $\alpha$, citocina pró-inflamatória, além de participar na resposta imunológica e na etiopatogenia de algumas neoplasias, também está envolvido na gênese da resistência à insulina, por inibir a fosforilação de receptores de insulina ${ }^{70}$. OTNF- $\alpha$ é expresso pelo tecido adiposo. Níveis elevados de TNF- $\alpha$ são encontrados em todos os modelos de obesidade genética em roedores e em obesos humanos ${ }^{71,72}$. Esta citocina também se expressa em quantidade maiores nas células musculares isoladas de diabéticos tipo $2^{72}$. Foi sugerido que o TNF- $\alpha$ atua como fator adipostático ${ }^{73}$ e que, na obesidade humana, parte deste efeito estaria envolvida nos mecanismos que levam à resistência à insulina. A ausência completa do TNF- $\alpha$ ou de seus receptores resulta em melhora significativa da sensibilidade à insulina em camundongos com obesidade induzida por dieta, hipotalâmica ou genética ${ }^{70,74}$.

Além de se registrar concentrações elevadas de TNF- $\alpha$ na obesidade ${ }^{75}$, a citocina aumenta a produção de endoteli- na- $1^{76,77}$ e de angiotensinogênio ${ }^{78}$, refletindo a disfunção endotelial que pode ocorrer em obesos hipertensos. OTNF- $\alpha$ atua em sinergismo com outras citocinas durante a ativação de processos inflamatórios ${ }^{79}$, o que pode ser uma das explicações da associação entre obesidade, resistência a insulina e aterosclerose.

\section{Resistina, elo adicional na história natural da obesidade, diabetes e doença cardiovascular?}

Embora se reconhecesse há algum tempo que o diabetes tipo 2 está associado ao excesso de tecido adiposo peritoneal e à resistência à insulina, tanto em humanos como em modelos experimentais da doença, a causa última desta relação permanecia mal definida. Considerava-se que os ácidos graxos livres provenientes dos adipócitos, por inibirem a captação de glicose pelos músculo esquelético, eram a causa mais importante de resistência à insulina ${ }^{80}$. Mais tarde, proteínas e peptídeos também secretados pelo tecido adiposo passaram a ser apontados como agentes decisivos da insensibilidade à insulina em vários tecidos ${ }^{16,81}$. Porém, para os pesquisadores dessa área, sempre foi claro que outro elo ou elos adicionais poderiam existir para justificar, ao nível celular, a relação tão estreita entre resistência à insulina e obesidade.

Em 2000, um grupo de pesquisadores liderados por Claire Steppan ${ }^{82}$ da Universidade da Pensilvânia identificou no tecido adiposo um mediador que denominaram resistina (de resistência à insulina). Essa proteína, ao que tudo indica, poderá ser a explicação mais consistente dos eventos que levam à resistência à insulina. Trabalhando com uma das tiazoladinedionas, a rosiglitazona, em várias linhas celulares de adipócitos, caracterizaram um novo RNAm expresso pelo tecido adiposo e que era suprimido por este fármaco. Mostraram que a proteína codificada por este $R N A m$ se expressava exageradamente em vários roedores obesos, e que as tiazoladinedionas reduziam sua secreção tanto in vitro como na corrente circulatória de camundongos. Levantaram a hipótese que as tiazoladinedionas, pela sua ação sobre receptores nucleares gama ativados por proliferadores de peroxissomas, os PPAR- $\gamma$ modulariam a expressão de um gene específico do adipócito, a resistina, que estaria envolvido nas vias de sinalização moduladas pela insulina. Os PPAR- $\gamma$ pertencem a uma família de fatores de transcrição induzidos durante a diferenciação dos adipócitos e que atuam na sensibilidade dessas células à insulina ${ }^{83}$.

Contudo, numerosas dúvidas ainda existem sobre a resistina. Por exemplo, qual seria a ação da resistina em outros alvos fisiológicos da insulina além dos adipócitos, como o fígado, músculo e cérebro? Quais seriam as características de seu receptor e o papel da resistina na fisiologia normal? Como, exatamente, a sinalização resistino-mediada antagonizaria a sinalização insulino-mediada? Teria a resistina alguma interferência em processos que levam à proliferação de células musculares lisas, já que as tiazoladinedionas administradas in vivo inibem alterações morfológicas vasculares? ${ }^{84}$ É bastante provável que nos próximos anos a descoberta da 
resistina seja vista como um passo a mais no entendimento da obesidade, resistência à insulina, diabetes e, talvez, das alterações vasculares precoces tão freqüentes nessas doenças.

\section{Excesso de tecido adiposo, resistência às ações da insulina e risco cardiovascular}

A insulina é o regulador crítico de vários aspectos da biologia dos adipócitos, sendo essas células extremamente sensíveis ao hormônio. A insulina promove aumento da síntese de triglicerídeos pelos adipócitos, estimula o transporte de glicose e a diferenciação de pré-adipócitos em adipócitos, além de participar da captação de ácidos graxos provenientes de lipoproteínas circulantes ${ }^{85}$. Os efeitos metabólicos da insulina são modulados por uma gama de ações tecido-específicas, envolvendo rápidas mudanças na fosforilação de proteínas ${ }^{86}$. $\mathrm{O}$ termo resistência à insulina conota resistência às ações do hormônio na captação, metabolismo ou armazenamento de glicose ${ }^{87}$. Para muitos, a resistência à insulina seria o elo entre obesidade e diabetes 2 e, portanto, o regente do quarteto da morte (resistência à insulina, obesidade, dislipidemia e hipertensão arterial).

Na obesidade, a resistência à insulina se caracteriza por redução do transporte e metabolismo da glicose tanto nos adipócitos quanto no músculo esquelético e musculatura lisa vascular, comprometendo também a supressão da produção de glicose pelo fígado ${ }^{88}$. Estes defeitos funcionais resultam da sinalização deficiente da insulina nos três tecidos-alvo. Adicionalmente, parece haver nos adipócitos de obesos, importante comprometimento da regulação do principal transportador de glicose, os GLUT-4. A ligação da insulina ao seu receptor, a fosforilação do receptor, a atividade da tirosinaquinase e a fosforilação dos substratos de receptores de insulina, também estariam diminuídas ${ }^{89}$. Um mecanismo para explicar os defeitos na sinalização da insulina na obesidade seria o da expressão e ativação de várias proteínas tirosinafosfatase (PTPs), que defosforilam resíduos tirosina dos receptores de insulina, interrompendo a sinalização propagada pelos eventos de fosforilação em tais resíduos ${ }^{89}$.

A insulina compartilha, com a leptina, alvos neuroquímicos e anatômicos no hipotálamo medial, sendo considerada um sinal adipostático endógeno, induzindo redução no consumo alimentar ${ }^{52}$. Tanto a insulina como a leptina parecem ser fatores de risco de moléstia cardiovascular, quando associadas à resistência à insulina. Um exemplo ilustrativo deste fato vem de um estudo populacional realizado em Samoa, onde se registrou alta prevalência de diabetes não insulino-dependente e obesidade que se correlacionaram fortemente aos elevados níveis de leptina ${ }^{90,91}$.

\section{Insulina, molécula aterogênica?}

Uma meta-análise recentemente publicada, que avaliou 12 estudos prospectivos, mostrou que a hiperinsulinemia é um indicador de risco cardiovascular. Esta relação, ainda que não tivesse sido das mais consistentes, foi mais evidente em indivíduos de meia idade que nos idosos, em brancos mais que em negros, e dependente do tipo de ensaio utilizado para se medir a insulina ${ }^{92}$.

Os efeitos hemodinâmicos da insulina se associam intimamente às suas ações metabólicas. O hormônio é vasodilatador e a captação de glicose depende do fluxo sangüíneo da própria musculatura esquelética ${ }^{93}$. Scherrer e cols. ${ }^{94}$ demonstraram que a vasodilatação, pelo menos em pessoas saudáveis, é dependente do óxido nítrico, sendo atenuada pela administração de um inibidor da óxido nítrico sintase, $o$ L-NMMA.

Do ponto de vista de transdução de sinal da insulina, a mediação da vasodilatação é feita pela via do fosfatidil-inositol 3-quinase $\left(\mathrm{Pl}_{3} \mathrm{~K}\right.$, do inglês phosphatidilinositol 3kinase ${ }^{95}$. Numerosos trabalhos experimentais já evidenciaram que o óxido nítrico tem propriedades anti-aterogênicas ${ }^{96}$, diminui a migração e crescimento de células musculares lisas dos vasos ${ }^{97} \mathrm{e}$ inibe a agregação de plaquetas ${ }^{98}$. Outro mecanismo proposto para explicar as ações vasodilatadoras da insulina seria pela sua intervenção sobre o transporte de cálcio, reduzindo o trânsito intracelular do cationte e diminuindo o cálcio intracelular ${ }^{99}$.

Nos estados resistentes à insulina, a vasodilatação por ela modulada estaria comprometida, possivelmente devido a síntese inadequada de óxido nítrico pelo endotélio. Petrie e cols. ${ }^{100}$ descreveram uma relação direta entre a insensibilidade à insulina e a síntese de óxido nítrico em indivíduos saudáveis do sexo masculino. Baron e cols. ${ }^{93}$, anteriormente, já haviam relatado relação inversa entre o aumento do fluxo sangüíneo de membros inferiores em resposta a insulina e a pressão arterial média basal.

Em 1996, foi publicado o resultado do Insulin Resistance Atherosclerosis Study (IRAS), realizado em 1.400 indivíduos, que mostrou significativa associação negativa entre a sensibilidade à insulina e a espessura mio-intimal da carótida, provável indicador da presença de coronarioesclerose $^{101}$.

Os mecanismos fisiopatológicos que levam a proliferação mio-intimal e aterosclerose em pacientes com excesso de adiposidade visceral e resistência à insulina, embora especulativos, têm proposições baseadas em trabalhos experimentais e epidemiológicos.

Admite-se que o papel de importante agente mitogênico da insulina, ativado pela MAPK (mitogen-activated protein kinase), resulte em proliferação das células da musculatura lisa vascular ${ }^{102}$. Por outro lado, a inibição seletiva da via MAPK atenua o crescimento das células musculares lisas. É possível que, em pacientes com resistência à insulina, a ação promotora da mitogênese vascular da insulina se ative (fig. 3 ), e interações entre ela e outros mediadores de crescimento vascular ocorram. Por exemplo, a indução de hiperinsulinemia, combinada a hiperglicemia e hipertrigliceridemia, aumenta os níveis de PAI-1 de indivíduos normais ${ }^{103}$.

O Atherosclerosis Risk in Communities Study (ARIC) analisou os efeitos da associação de hiperinsulinemia, hiperglicemia e hipertrigliceridemia sobre o endurecimento arterial avaliado por ultra-sonografia, em 4.700 indivíduos de ambos os sexos. Os níveis de insulina em jejum associaram- 
se, independentemente, ao espessamento arterial, especialmente em pacientes brancos ${ }^{104}$.

Embora não existam evidências definitivas sobre a participação da insulina na etiopatogenia da doença cardiovascular aterogênica é bastante provável que suas ações mitogênicas sobre componentes da parede arterial se manisfestem particularmente na população de obesos e diabéticos e que associações sinergísticas com outros mediadores celulares acelerem o processo.

\section{Tecido adiposo e hipertensão arterial}

O excesso de tecido adiposo é considerado atualmente um dos fatores de risco mais importantes na gênese da hipertensão arterial essencial ${ }^{105}$. Já em 1987, os pesquisadores de Framingham, estudando os precursores que levavam ao aumento pressórico em adultos jovens (20-49 anos), mostraram que o maior preditor da hipertensão foi a hipertensão arterial medida no primeiro exame, e que $78 \%$ dos casos de hipertensão em homens e $65 \%$ dos casos em mulheres, podiam ser atribuídos diretamente à obesidade ${ }^{106}$. Em alguns grupos étnicos, como mulheres negras americanas, a prevalência de obesidade é de 70 a $80 \%$ coincidindo com a prevalência de hipertensão, que vai além de $70 \%{ }^{107}$. Por outro lado, redução de $10 \%$ do peso, sem intervenções de outra natureza, pode reduzir, e mesmo normalizar a pressão arterial de obesos ${ }^{105,108}$. Modelos experimentais de obesidade, seja por consumo de dieta com alto teor de gordura ou por mutações em genes responsáveis pelo controle do apetite, são acompanhados de hipertensão arterial ${ }^{105}$.

\section{Obesidade, sódio e hipertensão arterial}

Muitos obesos hipertensos são caracterizados como indivíduos sódio-sensíveis. A reabsorção tubular excessiva de sódio vem sendo apontada como mecanismo inicial básico do aumento da pressão arterial de obesos. Rocchini e cols. ${ }^{109}$ há alguns anos e posteriormente Hall e cols. ${ }^{105}$ demonstraram que o obeso dependia da elevação da sua pressão arterial para manter um balanço de sódio adequado, mostrando uma curva pressão-natriurese anormal desviada para a direita.

O desvio da curva pressão-natriurese seria resultante do aumento da reabsorção renal de sódio, bem como de valores mais elevados do ritmo de filtração glomerular e do flu-

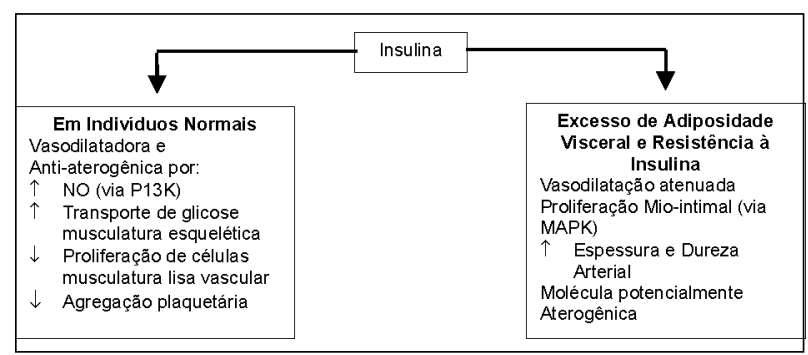

Fig. 3 - Efeitos vasculares da insulina em indivíduos normais e em pacientes com excesso de adiposidade visceral. P13K- fosfatidil-inositol 3 - kinase; MAPKmitogen actived protein kinase. Adaptado de Makhail e Tuck ${ }^{102}$. xo plasmático renal. A obesidade ativaria o SNS e o SRA, causaria resistência à insulina e hiperinsulinemia, que favoreceriam os aumentos da reabsorção tubular de sódio e da pressão arterial ${ }^{110}$.

O desvio da curva pressão-natriurese também poderia ser atribuído a mudanças estruturais e funcionais da medula renal - aumento de células intersticiais e matriz extracelular, que comprimiriam a alça de Henle e vasa recta, aumentando a reabsorção tubular de sódio e ativando o sistema renina-angiotensina ${ }^{111}$.

O aumento do conteúdo de sódio intracelular de obesos hipertensos está associado a anormalidades do seu manuseio no interior da célula ${ }^{112}$. Seria o defeito primário de hipertensos sódio-sensíveis com sobrepeso ${ }^{113}$. Estudos de Friedman e cols. demonstraram que o sódio intraeritrocitário reflete o conteúdo de sódio de células renais, podendo ser utilizado como marcador da sensibilidade ao sódio ${ }^{114}$. A elevação no conteúdo de sódio intracelular promoveria aumento da saída de íons hidrogênio do citosol graças a atividade da bomba de sódio-hidrogênio, elevando o $\mathrm{pH}$ intracelular ${ }^{105}$. O aumento do pH estimularia a ação de fatores de crescimento sobre células musculares lisas causando menor saída de cálcio do citosol pela diminuição da atividade da bomba de troca de cálcio e sódio ${ }^{115}$. Estes eventos levariam a vasoconstrição, aumento da resistência periférica e da pressão arterial ${ }^{115}$.

A atividade da sódio-potássio ATPase pode estar relacionada à maior sensibilidade ao sódio induzida pela obesidade. Em estudo realizado no Laboratório de Fisiopatologia Clínica e Experimental - CLINEX encontrou-se, em indivíduos obesos, correlação significativa do conteúdo de sódio-intraeritrocitário e da atividade da sódio-potássio ATPase com a relação cintura-quadril (fig. $4 \mathrm{~A} \mathrm{e} \mathrm{B}$ ) ${ }^{116}$. Além disso, a distribuição de gordura corporal e o conteúdo de sódio intraeritrocitário estiveram diretamente associados aos maiores níveis de pressão arterial e insulina de jejum e pós-prandial. Em outro estudo, utilizando-se o mesmo grupo de pacientes encontrou-se associação significativa entre o índice de massa corporal e a circunferência da cintura com a atividade da $\mathrm{Ca}^{2+}+\mathrm{Mg}^{2+}$ ATPase e níveis de sódio intraeritrocitário ${ }^{117}$.

\section{Hiperatividade simpática vs obesidade visceral}

O bloqueio farmacológico da atividade adrenérgica controla a hipertensão tanto em obesos humanos como em cães ou coelhos tornados obesos por dieta apropriada ${ }^{118,119}$, sugerindo que o SNS teria um papel importante na etipatogenia da doença. Experimentalmente, tem-se mostrado que cães alimentados com dieta rica em gordura acabam hipertensos, retendo mais sódio que seu congênere magro. Quando se denerva um dos rins desses animais, o rim intacto retém quase 2 vezes mais sódio que o rim denervado. Se a denervação for bilateral, a retenção de sódio não ocorre e a pressão se normaliza ${ }^{120}$.

O Normative Aging Study (avaliação epidemiológica realizada com 752 pacientes entre 40 a 90 anos de idade) mostrou em pacientes cujos níveis de insulina e excreção 


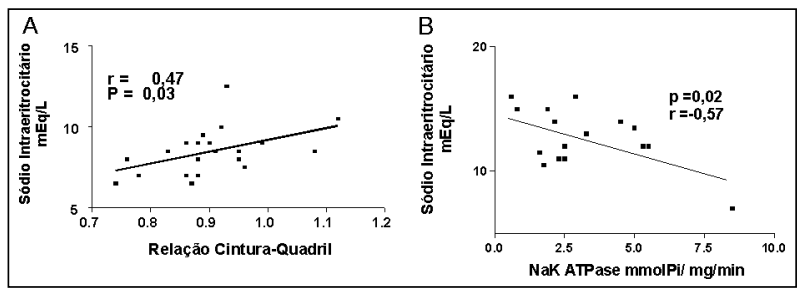

Fig. 4-A) Correlação entre a adiposidade abdominal, estimada pela relação cinturaquadril em 24 pacientes obesos hipertensos e o conteúdo de sódio intraeritrocitário. B) Correlação entre a atividade da bomba de sódio (NaK ATPase) e o conteúdo de sódio intraeritrocitário. Adaptado de Barroso SG, e cols. ${ }^{116}$.

urinária de norepinefrina situavam-se no tercil mais alto, que a incidência de hipertensão era de $35 \%$, sendo $10 \%$ nos pacientes do tercil mais baixo ${ }^{121}$. Embora esses resultados sejam especulativos quanto ao papel de agente causador do SNS sobre a hipertensão arterial de obesos, os resultados oferecem evidências epidemiológicas de associação entre insulina, atividade simpática e pressão arterial.

A mensuração de norepinefrina e epinefrina na urina e no plasma não é o indicador ideal da atividade simpática, já que, após a liberação de norepinefrina, ela é rapidamente recaptada e apenas uma fração atinge a circulação periférica $^{122}$. Este fato estimulou o aparecimento de outros métodos para avaliar o SNS, principalmente em humanos, destacando-se, entre eles, o spillover de norepinefrina que estima o clearance e transbordamento de moléculas de norepinefrina em circulações regionais (coração e rim, por exemplo), o registro da atividade simpática de nervos da pele e musculatura esquelética, que habitualmente utiliza o nervo peronero para este fim, e a análise espectral da variabilidade da freqüência cardíaca, que mede indiretamente a atividade do SNS ${ }^{123-125}$. Embora sejam métodos que ainda apresentam elevado coeficiente de variação, invasivos e restritos a laboratórios de pesquisa, têm sensibilidade e especificidade maiores que a excreção urinária e concentrações plasmáticas de norepinefrina e epinefrina.

O spillover de norepinefrina renal, por exemplo, está aumentado em obesos normotensos, embora o spillover cardíaco neste mesmo grupo esteja diminuído ${ }^{126}$. Tem-se proposto um possível efeito causal da hiperatividade simpática renal para explicar a hipertensão em obesos ${ }^{126}$. Em contrapartida, vários estudos microneuroradiográficos mostraram hiperatividade simpática muscular em obesos normotensos, mas não diferenças significativas entre obesos normo e hipertensos ${ }^{127,128}$, o que poderia ser um argumento contra a participação de uma hiperatividade simpática regional na gênese da hipertensão associada à obesidade.

Em obesos não hipertensos, a atividade simpática, avaliada tanto por estudos epidemiológicos, como por abordagens que estimam o SNS regional, mostra-se claramente aumentada. É possível que estudos seqüenciais, em várias fases evolutivas da hipertensão do obeso (a partir dos primórdios quando o processo hipertensivo é discreto e intermitente, sem que ainda reajustes estratégicos entre os sistemas tenham ocorrido) venham confirmar que o SNS inicia ou contribui, de modo decisivo, na evolução de eventos hemodinâmicos e metabólicos.

\section{Leptina e controle da pressão arterial}

A administração de leptina, embora aumente a atividade simpática, nem sempre eleva os níveis de pressão arterial $^{129,130}$. A explicação para este aparente paradoxo reside no fato de que a leptina também estimularia a produção de óxido nítrico através da expressão de seus receptores em células endoteliais, o que justifica seu efeito vasodilatador a curto prazo ${ }^{131,132}$. Diferentes mecanismos estão envolvidos na ação vasodilatadora da leptina, passando por efeitos dependentes da liberação de óxido nítrico, ocorrida particularmente em vasos condutores, e pela liberação do fator hiperpolarizante derivado do endotélio, que se registra em vasos de resistência ${ }^{132}$.

Quando houver defeito no transporte ou nos receptores de leptina, como ocorre em camundongos $d b / d b$ e, provavelmente, em muitos casos de obesidade humana, a resposta endotelial à administração periférica de leptina não se faz ${ }^{131}$. Por outro lado, estudos agudos em roedores mostraram que a inibição da síntese de óxido nítrico não potencializa os efeitos pressóricos de leptina, sugerindo que seus efeitos vasorelaxadores seriam mediados pelo fator hiperpolarizante derivado do endotélio ${ }^{132}$. Em situações em que não houvesse esse efeito contra - regulador do endotélio, a resposta ao aumento da atividade simpática leptino-induzida surgiria plenamente, traduzindo-se em elevação pressórica.

A administração crônica de leptina, intravenosamente ou por infusão intracarotídea, a ratos não obesos, de modo a aumentar sua concentração sérica a níveis semelhantes aos de portadores de obesidade severa, eleva significativamente a pressão arterial e a freqüência cardíaca, a despeito de reduzir o consumo calórico ${ }^{130}$. Esse modelo de hipertensão leptino-induzida tem sido estudado principalmente pelo grupo de Hall e cols. que mostrou que as repercussões a longo prazo do peptídeo sobre a pressão arterial seriam ajustadas pela ativação simpática, já que o bloqueio $\alpha$ e $\beta$ adrenérgicos aboliria completamente as mesmas, embora não alterasse suas ações sobre o apetite e perda de peso ${ }^{133}$.

A hiperinsulinemia observada na síndrome de resistência à insulina pode ser o fator chave da hiperleptinemia ${ }^{134}$ e das anormalidades metabólicas ${ }^{135}$ de obesos. A insulina é importante estimulo à produção de leptina, sendo ambas indispensáveis à homeostasia bariátrica. Resistência a ação de ambas as moléculas, que resulta em hiperinsulinemia e hiperleptinemia, configuraria o perfil da maior parte de obesos humanos ${ }^{136}$.

Estudos realizados em nosso laboratório em pacientes obesos e hipertensos, na faixa etária entre 25 e 65 anos de idade, mostraram correlação significativa entre a leptina e área sob a curva de insulina, e entre leptina e pressão arterial média e diastólica (fig. 5 A, B e D) ${ }^{137}$. Nesse estudo a leptina também se associou ao sódio intracelular. Já foi demonstrado que concentrações elevadas de leptina e insulina estimulam a atividade simpática em indivíduos obesos, elevando a pressão arterial e aumentando o risco de doença cardiovascular $^{128}$. 
O elo de ligação entre leptina, insulina e atividade simpática, parece ser mais evidente durante o envelhecimento, o que seria uma explicação plausível para o maior risco de doença cardiovascular nessa faixa etária ${ }^{138}$. Este fato foi confirmado por nós no mesmo grupo de obesos hipertensos, nos quais registrou-se correlação significativa entre a idade e os níveis de leptina (fig. 5 C).

\section{Adiposidade abdominal e dislipidemia aterogênica}

A partir de 1988, com a clássica publicação de Gerald Reaven ${ }^{139}$ sobre o papel da insulina na etiologia da aterosclerose e suas complicações, um número crescente de trabalhos tem surgido na literatura mostrando que a resistência à insulina, marcador precoce dos eventos fisiopatológicos, que culminam em diabetes tipo 2, está, também, presente em obesos normoglicêmicos, em indivíduos sedentários ${ }^{140}$, naqueles com intolerância à glicose, em normoglicêmicos com história familiar de diabetes ${ }^{141} \mathrm{e} \mathrm{em} \mathrm{hiperten-}$ sos normoglicêmicos ${ }^{142}$. Reconhece-se, também, que a obesidade associada a dislipidemia e hipertensão é uma das causas mais importantes de morbi-mortalidade cardiovascular e por outras causas ${ }^{143}$. Contudo, o universo de obesos é heterogêneo. Alguns indivíduos, com índice de massa corpórea acima de $30 \mathrm{~kg} / \mathrm{m}^{2}$, não apresentam as complicações mencionadas, enquanto outros, com sobrepeso, mostram, prematuramente, hipertensão e doença cardiovascular.

Recentemente, estudos realizados em pacientes com lipodistrofia congênita generalizada mostraram que o tecido adiposo intraperitoneal é o que apresenta atividade metabólica mais intensa, quando comparado à atividade do tecido adiposo subcutâneo abdominal e retroperitoneal. Já o tecido adiposo branco de regiões anatômicas mais periféricas (por exemplo, nádegas e pernas) tem discreta atividade metabólica, exercendo funções estruturais de suporte e proteção ${ }^{14,145}$. Tem sido exaustivamente mostrado que quase

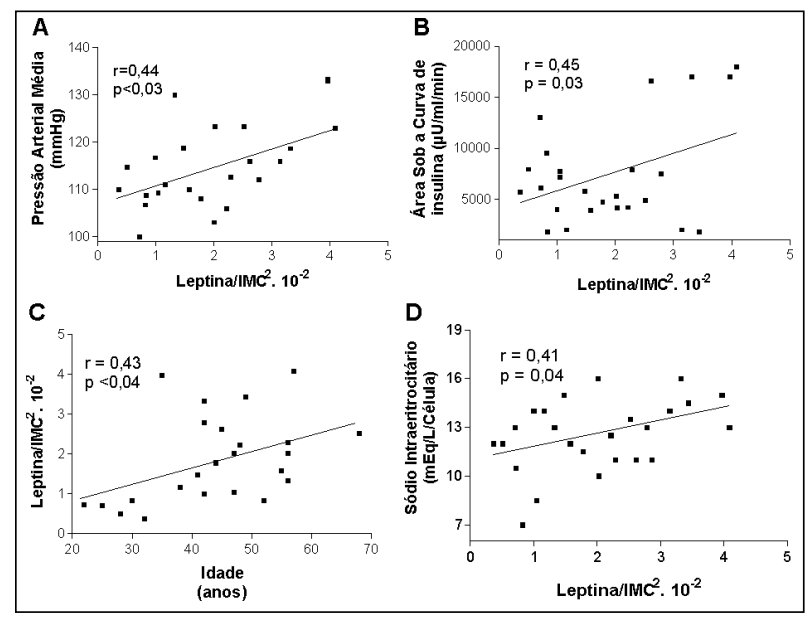

Fig. 5 - A razão leptina/IMC ${ }^{2}$ em 35 pacientes obesos hipertensos correlacionou-se direta e significativamente à pressão arterial média (A), área sob a curva de insulina (B) e conteúdo de sódio intraeritrocitário (D). A razão leptina/IMC ${ }^{2}$ aumentou com a idade $(\mathrm{C})$, o que indica possível resistência à leptina com o envelhecimento. Adaptado de Barroso SG, e cols. ${ }^{137}$. todas as etapas do metabolismo lipídico que se desenvolvem no tecido adiposo, tais como a atividade lipolítica hormônio dependente e mediada por fatores não humorais, a inibição da lipólise modulada pela insulina, a expressão da lipase hormônio sensível, a síntese de triglicerídeos e a atividade da lipase lipoprotéica, são peculiares ao tecido adiposo abdominal, principalmente o intraperitoneal, sendo modestas as do tecido adiposo de sustentação ${ }^{146}$.

A dislipidemia do obeso é caracterizada por uma série de anormalidades nas várias fases do metabolismo lipídico. A não supressão pós-prandial insulino-mediada de $\mathrm{AGL}$ aumenta o fluxo dos mesmos ao fígado, causando não só maior síntese e secreção de VLDL ricas em triglicerídeos como maior secreção de Apo B. Como foi visto, a resistência à ação da insulina quanto à supressão de AGL se acompanha de menor captação de glicose e hiperinsulinemia que se correlacionam significativamente com os níveis de triglicerídeos ${ }^{147,148}$. Além disso, os níveis pós-prandiais de AGL correlacionam-se inversamente com a atividade da lipase lipotroteíca (LPL) por conta de mecanismos locais de retroalimentação ${ }^{149}$. A LPL é essencial para o catabolismo de lipoproteínas ricas em triglicerídeos, incluindo quilomícrons e VLDL. Já se demonstrou que os AGL dissociam a LPL de seus sítios de ligação não só em seres humanos ${ }^{150}$, como em cultura de células endoteliais ${ }^{151}$. Deste modo, a atividade lipolítica reduzida é importante determinante do acúmulo de triglicerídeos no plasma.

No período pós-prandial do obeso, mudanças nas moléculas de lipases levam ao menor clearance de partículas ricas em triglicerídeos, que competem pela mesma via lipolítica ${ }^{152}$, resultando em excesso das mesmas na circulação, incluindo quilomícrons e seus remanescentes, que são estruturas de elevado potencial aterogênico ${ }^{153}$. A figura $6 \mathrm{~A}$ e B mostra os efeitos da resistência à insulina de pacientes com excesso de tecido adiposo visceral sobre o metabolismo de lípides e lipoproteínas.

Em obesos, concentrações elevadas de VLDL- triglicerídeos do fígado competem com os quilomícrons derivados da dieta pelas LPL, o que acaba por reduzir o clearance dos mesmos e dos quilomícrons remanescentes. Além disso, numerosos estudos apontam que a maior parte dos obesos consome dietas de elevado teor em gordura, sob a forma de ácidos graxos saturados e colesterol ${ }^{154,155}$, contribuindo para maiores concentrações de lipídeos no período pósprandial.

Durante o período pós-prandial, as proteínas de transferência de ésteres de colesterol (CETP) promovem a troca de triglicerídeos das VLDL para as moléculas de $\mathrm{HDL}_{2}$-colesterol. Reciprocamente, observa-se o intercâmbio de ésteres de colesterol com as VLDL ${ }^{156}$ (fig. 6B). Concentrações séricas aumentadas de triglicerídeos e AGL amplificam esse processo de transferência ${ }^{157}$, o que resulta em maior conversão das $\mathrm{HDL}_{2}$ ricas em triglicerídeos (via lipase hepática) em $\mathrm{HDL}_{3}$, diminuindo os níveis das $\mathrm{HDL}_{2}$-colesterol cardioprotetoras ${ }^{158}$. Por outro lado, as CETP transferem triglicerídeos às partículas de LDL, resultando em rearranjo na estrutura molecular dessas proteínas, que se tornam meno- 


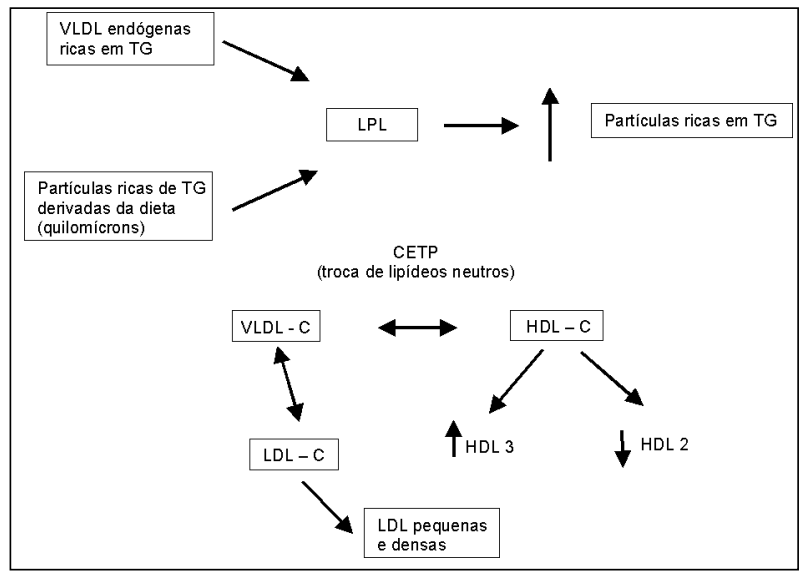

Fig. 6 - A) As partículas enriquecidas de triglicerídeos (TG) tanto endógenas (VLDL) como derivadas da dieta (quilomícrons) competem pelas moléculas de lipase lipoprotéica (LPL) da via lipolítica, contribuindo para a hipertrigliceridemia. B) A troca de lipídios neutros entre VLDLC e HDLC via proteínas de transferência de ésteres de colesterol (CETP) resulta em diminuição das HDL2 cardioprotetoras. A troca de lipídios neutros entre VLDLC e LDLC resulta em partículas de LDL pequenas e densas de elevado potencial aterogênico. Adaptado de Ami Laws ${ }^{161}$.

res e densas ${ }^{159}$. Hipertrigliceridemia pós-prandial e lipoproteínas ricas em triglicerídeos são, portanto, os determinantes dos níveis de LDL pequenas e densas ${ }^{160}$, que se associam, independentemente de outros fatores de risco, com maior incidência de DCV aterogênica ${ }^{161}$.

Nos últimos 12 anos, o grupo de Després e cols. ${ }^{162-164}$ do Lipid Research Center de Quebéc, tem mostrado com muita clareza, que o obeso com excesso de tecido adiposo visceral apresenta uma constelação de alterações metabólicas que incluem hipertrigliceridemia, valores normais ou marginalmente anormais de LDL-colesterol e diminuição nas concentrações de HDL-colesterol. A despeito de valores normais de LDL-colesterol ou marginalmente anormais, esses pacientes exibem um aumento de 15 a 20\% de Apo B, indicando a existência de partículas de LDL mais densas e menores ${ }^{165}$. Embora essas anormalidades sejam encontradas em pacientes com diabetes tipo 2, aparecem, freqüentemente, em obesos resistentes à insulina. Després e cols. descrevem esta condição como síndrome dislipidêmica de resistência à insulina associada à obesidade.

Numerosos trabalhos desse grupo têm divulgado a natureza aterogênica da dislipidemia do obeso resistente à insulina. O Quebéc Heart Study ${ }^{166}$ mostrou que a hiperinsulinemia e níveis elevados de Apo B são fatores preditivos de risco de doença isquêmica miocárdica, aumentando em 11 vezes as chances de coronariopatia. No mesmo estudo, observou-se que a presença, no plasma de partículas de LDL pequenas e densas, e níveis de Apo B superiores ao quartil $50 \%$ aumentava em 6 vezes o risco de angina de peito, infarto do miocárdio e morte relacionada a doença isquêmica miocárdica ${ }^{167}$. Já a tríade de fatores metabólicos de risco considerados não convencionais -hiperinsulinemia, níveis elevados de Apo B e LDL pequenas e densas elevou em 18 vezes o risco de doença coronariana, mesmo após ter-se ajustado a análise para os triglicerídeos plasmáticos, HDLcolesterol e LDL-colesterol ${ }^{168}$.
Muitos pacientes com resistência à insulina têm excelente capacidade de síntese e secreção de insulina pelas células $\beta$ pancreáticas e não demonstram, por isso, nenhuma alteração da sua homeostase glicêmica. Foi proposto que a insulina em jejum é um meio simples e o melhor marcador, embora não perfeito, da síndrome de resistência à insulina em pacientes não diabéticos com excesso de adiposidade visceral ${ }^{168}$. Quanto à dislipidemia aterogênica, observa-se, na prática clínica, que os pacientes com hipertrigliceridemia e HDL baixo têm LDL pequenas e densas. As duas variáveis citadas, hoje mensuradas na maior parte dos laboratórios de análises clínicas podem antecipar, quando associadas a hiperinsulinemia em jejum e a níveis alteados de Apo B, a presença do fenótipo de LDL pequenas densas. As concentrações de Apo B são o melhor marcador de lipoproteínas aterogênicas. Podem ser substituídas pela razão colesterol total/HDL-C quando não estiverem disponíveis.

Embora se aceite cada vez mais que fatores de risco não tradicionais aumentem as possibilidades de doença isquêmica miocárdica, discute-se se a síndrome de resistência à insulina seria tão aterogênica quanto as concentrações elevadas de LDL-colesterol. Tentando responder esta questão Gaudet e cols. ${ }^{169}$, em 1998, avaliaram, em um grupo de 120 pacientes com hipercolesterolemia familiar e nãodiabéticos, a presença de coronariopatia significante através de angiografia (obstrução de mais de $50 \%$ da luz de uma das coronárias). Notaram que a presença de obesidade abdominal, combinada à hiperinsulinemia, aumentava o risco de doença isquêmica miocárdica em 13 vezes enquanto naqueles com hipercolesterolemia familiar, mas sem obesidade abdominal e hiperinsulinemia, esse aumento foi de 2 vezes. Esses resultados mostraram que os níveis plasmáticos de LDL-colesterol são um fator de risco maior de doença isquêmica miocárdica. Porém, em universo homogêneo de portadores de um mesmo defeito molecular nos receptores de LDL e que cursam com hipercolesterolemia severa, a hiperinsulinemia e a obesidade abdominal são igualmente importantes marcadores de risco.

Estudo realizado recentemente na Filândia, com 23 gêmeos idênticos, (um dos pares discordante em média $18 \mathrm{~kg}$ quanto ao excesso de peso), avaliou a possibilidade de existir um componente genético que explicaria as alterações no metabolismo de lipoproteínas. Os gêmeos obesos demonstraram aumento de $20 \%$ nas LDL-C, diminuição de $20 \%$ na subfração HDL-C, e significativa elevação de $90 \%$ em homens, e $35 \%$ em mulheres, no colesterol total, VLDL e triglicerídeos, $18 \%$ de incremento na atividade da lecitina aciltransferase e $38 \%$ de aumento na atividade da lipase hepática. Concluíram que quando fatores genéticos são idênticos, a obesidade associa-se significativamente ao perfil aterogênico ${ }^{170}$.

Conclusões: 1) O tecido adiposo já não é mais considerado apenas uma estrutura de sustentação e proteção. Nos últimos 10 anos inúmeras pesquisas mostraram que nele se expressa intensa atividade metabólica e endócrina; 
2) na tentativa de se identificar os componentes do sistema homeostático que regula o peso corporal, inúmeros genes foram caracterizados, incluindo vários responsáveis pela obesidade de animais e seres humanos. Desses, os que regulam a síntese de leptina pelo tecido adiposo têm importância central nos mecanismos lipostáticos. A leptina atua em neurônios do sistema nervoso central e modula a secreção de moléculas orexígenas como o neuropeptídeo Y e a agouti-related protein, e a secreção de mediadores que controlam o apetite, como a melanocortina e transcriptos regulados pela cocaína e anfetamina; 3 ) o tecido adiposo sintetiza angiotensina II e aloja em sua membrana a sub-unidade AT1 do receptor da angiotensina. É provável que os componentes do sistema renina-angiotensina dos adipócitos participem da fisiopatologia da hipertensão e doença cardiovascular do paciente com sobrepeso e obesidade; 4) o tecido adiposo sintetiza e secreta vários outros mediadores e citocinas, entre eles a adipsina, o TNF- $\alpha$, transportadores intracelulares de glicose, receptores gama ativados por proliferadores de peroxissomas e a resistina, que participam de mecanismos que levam a dislipidemia, resistência à insulina, hipertensão e aterosclerose; 5) o excesso de tecido adiposo, principalmente o visceral, representa uma ameaça à expectativa de vida. Alguns estudos epidemiológicos e fisiopatológicos têm mostrado que a deposição visceral de tecido adiposo é um fator maior de risco no desenvolvimento de hipertensão arterial, resistência à insulina, hiperinsulinemia e diabetes mellitus tipo 2. Freqüentemente, o obeso é hiperinsilinêmico e hiperleptininêmico e resistente às ações de ambos os hormônios. Suspeita-se que a insulina seja uma molécula aterogênica e que a leptina eleve a pressão arterial, por aumentar a atividade do sistema nervoso simpático. O excesso de adiposidade visceral se associa à hipertrigliceridemia, diminuição do HDL$\mathrm{C}$, aumento da Apo B e das LDL pequenas e densas, e com níveis de LDL-C normais ou marginalmente anormais. Este tipo de dislipidemia, particular ao obeso resistente à insulina, aumenta consideravelmente o risco de angina de peito e morte relacionado a doença isquêmica miocárdica por coronarioesclerose.

\section{Referências}

1. Vague J. La differenciation sexuelle: facteur determinant des formes de l'obesite. La Presse Medicale 1947; 55: 339-40.

2. Vague J. The degree of masculine differentiation of obesities: a factor determining predisposition to diabetes, gout, and uric calculous disease. Am J Clin Nutr 1956; 4: 20-34.

3. Lapidus L, Bengtsson C, Larsson B, Pennert K, Ryho E, Agostrom L. Distribution of adipose tissue and risk of cardiovascular disease and death: A 12-year follow-up of participants in the population study of women in Gothenburg. BMJ 1984; 289: 1257-61.

4. Ducimetiere P, Richard J, Cambien F. The pattern of subcutaneous fat distribution in middle-aged men and the risk of coronary heart disease: the Paris prospective study. Int J Obes 1986; 10: 229-40.

5. Donahire RP, Bloom E, Abbot RD, Reed DM, Yans K. Central obesity and coronary heart disease in men. Lancet 1987; 1: 821-3.

6. Hall JE, Brands MW, Dixon WN, Smith MJ Jr. Obesity-induced hypertension: renal function and systemic hemodynamics. Hypertension 1993; 22: 292-9.

7. Ward KD, Sparrow D, Landsberg L, Young JB, Weiss ST. The influence of obesity, insulin, and sympathetic nervous system activity on blood pressure. Clin Res 1993; 2: 168A.

8. Rumantir MS, Vaz M, Jennings GL, et al. Neural mechanism in human obesity-related hypertension. J Hypertens 1999; 17: 1125-33.

9. Mohamed-Ali V, Pinkney JH, Coppack SW. Adipose Tissue as an endocrine and paracrine organ. Int J Obesity 1998; 22: 1145-58.

10. Loskutoff DJ, Samad F. The adipocyte and hemostatic balance in obesities. Studies of PAI-1. Arterioscler Thromb Vasc Biol 1998; 18: 1-6.

11. Cooper RN, Mc Farlane-Anderson N, Bennett FI, et al. ACE, angiotensinogen and obesity: a potential pathway leading to hypertension. J Hum Hypert 1997; 11: 107-11.

12. Crandall DL, Herzlinger HE, Saunders BD, Kral JG. Developmental aspects of the adipose tissue renin-angiotensin system: therapeutic implications. Drug Dev Res 1994; 32: 117-25.

13. Hotamisligil GS, Spiegelman BM, Adipose expression of tumor necrosis factor-alpha: direct role in obesity-linked insulin resistance. Science 1993; 259: 87-91.

14. Cianflone K, Roncari DAK, Maslowska M, Baldo A, Forden J, Sniderman AD. The adipsin-acylation stimulating protein system in human adipocytes: regulation of triacylglycerol synthesis. Biochemistry 1994; 33: 9489-95.

15. Baldo A, Sniderman AD, St-Luce S, et al. The adipsin-acylation stimulating protein system and regulation of intracellular triglyceride synthesis. J Clin Invest 1993; 92: 1543-7.
16. Gregoige FM, Smas CM, Sul HS. Understanding adipocyte differentiation. Physiol Rev 1998; 78: 783-809.

17. Bray GA. Health hazards of obesity. Endocrinol Metab Clin North Am 1996;25: 907-19.

18. World Health Organization MONICA Project. Geographical variation in the major risk factors of coronary heart disease in men and women aged 35-64 years. World Health Stat Quart 1988; 41: 115-40.

19. Folson AR, Kaye AS, Sellors TA. Body fat distribution and 5-year risk of death in older women. JAMA 1993; 269: 483-7.

20. Coleman DL. Obesity and diabetes: Two mutants genes causing diabetes-obesity syndromes in mice. Diabetologia 1978; 14: 141-8.

21. Harris RB, Hervey E, Hervey GR, Tobin G. Body composition of lean and obese Zucker rats in parabiosis. Int J Obesity 1987; 11: 275-83.

22. Truett GE, Bahary N, Friedman JM. Rat obesity gene fatty (fa) maps to chromossome 5: Evidence for homology with the mouse gene diabetes (db). Proc Natl Acad Sci USA 1991; 88: 7806-9.

23. Yen TT, Gill AM, Frigeri LG, Barsh GS, WolffGL. Obesity, diabetes, and neoplasia in yellow (A $A^{y}$ a )-mice: ectopic expression of the agouti gene. Faseb J 1994; 8: 543-52.

24. Zhang Y, Proenca R, Mafffei M, Barone M, Leopold L, Friedman JM. Positional cloning of the mouse obese gene and its human homologue. Nature 1994; 372: 425-32.

25. Chen G, Koyama K, Yuan X, et al. Disappearance of body fat in normal rats induced by adenovirus-mediated leptin gene therapy. Proc Natl Acad Sci USA 1996; 93: 14795-9.

26. Campfield LA, Smith FJ, Guisez Y, Devos R, Burn P. Recombinat mouse OB protein: evidence for a peripheral signal linking adiposity and central neural networks. Science 1995; 269: 546-9.

27. Campfield LA, Smith FJ. Overview. Neurobiology of OB protein (leptin). Proc Nutr Soc 1998; 57: 429-40.

28. Cinti S, De Matteis R, Picó C, et al. Secretory granules of endocrine and chiefcells of human stomach mucosa contain leptin. Int J Obes 2000; 24: 789-93.

29. Considine RV, Sinha MK, Heiman ML, etal. Serum immunoreactive-leptin concentrations in normal-weight and obese humans. N Engl J Med 1996; 334: 292-5.

30. Fagundes VGA, Barroso SG, Francischetti EA. Hipertensão e Obesidade. Hipertensão 1998; 1: 61-72.

31. Billington CJ, Levine AS. Shedding new light on obesity: appetite regulation. Curr Biol 1996; 6: 920-3.

32. Inui A. Feeding and body-weight regulation by hypothalamic neuropeptidesmediation of the actions of leptin. Trends in Neurosciences 1999; 22: 62-7.

33. Tartaglia LA. The leptin receptor. J Biol Chem 1997; 272: 6093-6. 
34. Considine RV, Considine EL, Williams CJ, Hyde TM, Caro JF. The hypothalamic leptin receptor in humans. Identification of incidental sequence polymorphisms and absence of db/db mouse and fa/fa rat mutations. Diabetes 1996; 45: 992-4.

35. Considine RV, Caro JF. Leptin and the regulation of body weight. Int J Biol 1997; 29: $1255-72$.

36. Larsson H, Ahren B. Short term dexamethasone treatment increases plasma leptin independently of changes in insulin sensitivity in healthy women. J Clin Endocrinol Metab 1996; 81: 4428-32.

37. Janik JE, Curti BD, Considine RV, et al. Interleukin 1a increases serum leptin concentrations in humans. J Clin Endocrinol Metab 1997; 82: 3084-6.

38. Zumbach MS, Wolfgang M, Boehme J, etal. Tumor necrosis factor increases serum leptin levels in humans. J Clin Endocrinol Metab 1997; 82: 4080-2.

39. Sih R, Morley JE, Kaiser FE, Perry HM III, Patrick P, Ross C. Testosterone replacement in older hypogonadal men: A 12-month randomized controlled trial. J Clin Endocrinol Metab 1997; 82: 1661-7.

40. Naggert J, Harris T, North M. The genetics of obesity. Curr Op Gen Dev 1997; 7: 398-404.

41. Friedman JM. Leptin, leptin receptors, and the control of body weight. Nutr Rev 1998; 56[2 part 2]: S38-S46.

42. Bray GA, York DA. Hypothalamic and genetic obesity in experimental animal. Physiol Rev 1979; 59: 719-809.

43. Bultman SJ, Michaud EJ, Woiychik RP. Molecular characterization of the mouse agouti locus. Cell 1992; 71: 1195-204.

44. Tsujii S, Bray GA. Acetylation alters the feeding response to MSH and beta-endorphin. Brain Res Bull 1989; 23: 165-9.

45. Roissi M, Kim MS, Morgan DG, et al. AC- terminal fragment of Agouti-related protein increases feeding and antagonists the effect of alfa-melanocyte stimulating hormone in vivo. Endocrinology 1998; 139: 4428-31.

46. Broberger C, Johansen J, Johasson C, Shalling M, Hockfelt T. The neuropeptide Y/ agouti generated protein (AGRP) brain cercuitry in normal, anoretic, and monosodium glutamate - treated mice. Proc Natl Acad Sci USA 1998; 95: 15043-8.

47. Gee CE, Chen CL, Roberts JL, Thompson R, Watson SJ. Identification of proopiomelanocortin neurones in rat hypothalamus by in situ cDNA-mRNA hybridization. Nature 1983; 306: 374-6.

48. Mobbs C, Mizuno T. Leptin regulation of proopiomelanocortin. Front Horm Res 2000; $26: 57-70$.

49. Cone RD. The central melanocortin system and energy homeostasis. Trends Endocrinol Metab 1999; 10: 211-6.

50. Fan W, Boston B, Kesterson R, Hruby V, Cone R. Role of melanocortinergic neurons in feeding and the agouti obesity syndrome. Nature 1997; 385: 165-8.

51. Huszar D, Lynch CA, Fairchild-Huntress V, et al. Targeted disruprion of the melanocortin -4 receptor results in obesity in mice. Cell 1997; 88: 131-41.

52. Schwartz MW, Wodds SC, Porte Jr D, Seeley RJ, Baskin DG. Central nervous system control of food intake. Nature 2000; 404: 661-71.

53. Flier JS, Harris M, Hollenberg AN. Leptin, nutrition, and the thyroid: the why, the wherefore, and the wiring. J Clin Invest 2000; 105; 859-61.

54. Cassis LA, Langher A, Fettinger M, et al. Cold exposure regulates renin-angiotensin system. J Pharmacol Exp Ther 1998; 286(suppl 2): 718-26.

55. Saye J, Ragsdale V, Carey R, Peach M. Localization of angiotensin peptide-forming enzymes of 3T3-F442A adipocytes. Amer J Physiol 1993; 264: C 1570$\mathrm{C}_{1} 1576$.

56. Safanova I, Aubert J, Negreal R, Ailhaud G. Regulation by fatly acids of angiotensinogen expression in preadipose cells. Biochem J 1997; 322(suppl 1): 235-9.

57. Aubert J, Darimont C, Safanova I, et al. Regulation by glucocorticoids of angiotensinogen gene expression and secretion in adipose cells. Biochem J 1997; 328: 701-6.

58. Aubert J, Safanova I, Negred R, Aihand G. Insulin down-regulates angiotensin gene expression and angiotensinogen secretion in cultured adipose cells. Biochem Biophys Res Commun 1998; 250(suppl 1): 77-82.

59. Shenoy U, Cassis L. Characterization of renin activity in brown adipose tissue. Amer J Physiol 1997; 272: 989-99.

60. Schlking P, Mallow H, Trindl A, Loffer G. Evidence for a local renin-angiotensin system in primary cultured human preadipocytes. Int J Obes Relat Metab Disord 1999; 23: 336-41.

61. Jones BH, Standrige MR, Taylor JN, Moustaid N. Angiotensin gene expression in adipose tissue: analysis of obese models and hormonal and nutritional control. Amer J Physiol 1997; 273: 236-42.

62. Cassis LA. Role of angiotensin II in brown adipose thermogenesis during cold acclimation. Am J Physiol 1993; 265: E860-E865.

63. Cassis LA, Fettinger M, Shenoy U. Characterization and regulation of angiotensin II receptors in rat adipose tissue. Cell Mol Asp of Angio Res 1996; 5: 39-47.

64. Cassis LA, Marchall DE, Fettinger MJ, et al. Mechanism contributing to angiotensin II regulation of body weight. Am J Physiol 1998; 274: E867-E876.

65. Jones BA, Stanbrige MR, Monstaid N. Angiotensin II increases lipogenesis in 3T3-L1 and human adipose cells. Endocrinology 1997; 138: 1512-9.
66. Shorr U, Blaschke K, Distler TS, Sharma AM. Rlationship between angiotensin, leptin and blood pressure in young normotesive men. J Hypertens 1998; 16: 1475-80.

67. Haffner SM, Fong D, Hazuda HP, Pugh JA, Patterson JK. Hyperinsulinemia, upper body adiposity, and cardiovascular risk factor in non-diabetics. Metabolism 1988; 37: 338-45.

68. Van Harmelen V, Ariapart P, Hoffstedt J, Lundkvist I, Bringman S, Arner P. Increased adipose angiotensinogen gene expression in human obesity. Obes Res 2000; 8: 337-41.

69. Cassis LA. Fat cell metabolism: Insulin, fatty acids, and renin. Current Hypertens Rep 2000; 2: 132-8.

70. Uysal KT, Wiesbrock SM, Marino MW, Hotamisligil GS. Protection from obesity-induced insulin resistance in mice lacking TNF-alpha function. Nature 1994; 389: 610-4

71. Kern PA, Saghizadech M, Ong JM, Bosh RJ, Ceem R, Simsolo RB. The expression of tumor necrosis factor in human adipose tissue. Regulation by obesity, weight loss, and relationship to lipoprotein lipase. J Clin Invest 1995; 95: 2111-9.

72. Saghizadech M, Ong JM, Garvey WT, Henry RR, Kern PA, The expression of TNF-a by human muscle. Relation to insulin resistance. J Clin Invest 1996; 97 : 1111-6.

73. Spiegelman BM, Hotamisligil GS. Through thick and thin: wasting obesity, and TNF- $\alpha$. Cell 1993; 7: 625-7.

74. Ventre J, Doebber T, Wu M, et al. Targeted disruption of the tumor necrosis factoralpha gene: metabolic consequences in obese and nonobese mice. Diabetes 1997; 46: 1526-31.

75. Pausova Z, Deslauriers B, Gaudet D, et al. Role of tumor necrosis factor-a gene locus in obesity and obesity-associated hypertension in French Canadians. Hypertension 2000; 36: 14-9.

76. Kahaleh MB, Fan PS. Effect of citokines on the production of endothelin by endothelial cells. Clin Exp Rheumatol 1997; 15: 163-7.

77. Winker G, Lakatos P, Salamon F, et al. Elevated serum TNF- $\alpha$ as a link between endothelial dysfunction and insulin resistance in normotensive obese patients. Diabetic Med 1999; 16: 207-11.

78. Brasier AR, Li J, Wimbish KA. Tumor necrosis factor activates angiotensinogen gene expression by the Rel A transactivator. Hypertension 1996; 27: 1009-17.

79. Bédard S, Marcotte B, Marette A. Cytokines modulate glucose transport in skeletal muscle by inducing the expression of inducible nitric oxide synthase. Biochem J 1997; 325: 487-93.

80. Boden G. Role of fatty acids in the pathogenesis of insulin resistance and NIDDM. Diabetes 1997; 46: 1-10.

81. Spiegelman BM, Flier JS. Adipogenesis and obesisty rounding out the big picture. Cell 1996; 87: 377-89.

82. Steppan CM, Bailey ST, Bhat S, et al. The hormone resistin links obesity to diabetes. Nature 2001; 409: 307-12.

83. Braissant O, Foufelle F, Seotto C, et al. Differential expression of peroxisome proliferator - activated receptors (PPARS): tissue distribution of PPAR - alpha, -beta, - gamma in the adult rat. Endocrinology 1996; 137: 354-66.

84. Yoshimoto T, Naruse M, Shizume H, et al. Vasculo-protective effects of insulin sensitizing agent pioglitazone in neointimal thickening and hyperetensive vascular hypertrophy. Atherosclerosis 1999; 145: 333-40.

85. Kahn BB, Flier JS. Obesity and insulin resistance. J Clin Invest 2000; 106 : 467-72.

86. Olesfsky JM. Treatment of insulin resistance with peroxisome prolifarator-activated receptor $\mathrm{g}$ agonists. J Clin Invest 2000; 106: 467-72.

87. Shulman GI. Cellular mechanisms of insulin resistance. J Clin Invest 2000; 106 171-6.

88. Reaven GM. Pathophysiology of insulin resistance in human disease. Physiol Rev 1995; 75: 473-86.

89. Goldstein BJ, Ahmad F, Ding W, Li PM, Zhang WR. Regulation of insulin signalling pathway by cellular protein-tyrosine phophatases. Mol Cell Biochem 1998; 182: 91-9.

90. Courten M, Zimmet P, Hodge A, et al. Hyperleptinemia: the missing link in the metabolic syndrome? Diabetes Med 1997; 14: 200-8.

91. Haynes WG, Morgan DA, Walsh AS, Sivitz WI, Mark AL. Cardiovascular consequences of obesity: role of leptin. Clin Experim Pharmacol Physiol 1998; 25 58-64

92. Ruige Ib, Assendelf WJJ, Dekker JM, et al. Insulin and risk of cardiovascular disease: a meta-analysis. Circulation 1998; 97: 996-1001.

93. Baron AD, Brechtel-Hood, Johnson A, Hardin D. Skeletal blood flow. A possible link between insulin resistance and blood pressure. Hypertension 1993; 21: 129-35.

94. Scherrer U, Randin D, Vollenweider P, et al. Nitric oxide release accounts for insulin's vascular effects in humans. J Clin Invest 1994; 94: 2511-5.

95. Hsueh W, Law R. Insulin signaling in the arterial wall. Am J Cardiol 1999; 84 $21 \mathrm{~J}-24 \mathrm{~J}$. 
96. Baron AD. Vascular reactivity. Am J Cardiol 1999; 84: 25J-27J.

97. Garg UC, Hassid A. Nitric oxide-generating vasodilators and 8-bromo-cyclic guanosine monophosphate inhibit mitogenesis and proliferation of cultured rat vascular smooth muscle cells. J Clin Invest 1989; 83: 1774-7.

98. Radomski MW, Moncada S. The biological and pharmacological role of nitric oxide in platelet function. Adv Exp Med Biol 1993; 344: 251-64.

99. Saito F, Hori MT, Fittingoff M, Tuck ML. Insulin attenuates agonist-mediated calcium mobilization in cultured rat vascular smooth muscle cells. J Clin Invest 1993; 92: 1161-8

100. Petrie JR, Ueda S, Webb D, et al. Endothelial nitric oxide production and insulin sensitivity. A physiological link with implications for pathogenesis of cardiovascular disease. Circulation 1996; 93: 1331-3.

101. Howard G, O'Leary DH, Zaccaro D, et al. Insulin sensitivity and atherosclerosis. Circulation 1996; 93: 1809-17.

102. Mikkail N, Tuck M. Insulin and the vasculature. Curr Hypertens Rep 2000; 2: 148-53.

103. Calles-Escadon J, Mirza SA, Sobel BE, Schneider DJ. Induction of hyperinsulinemia combined with hyperglycemia and hypertriglyceridemia increases plasminogen activator inhibitor 1 in blood in normal human subjects. Diabetes 1998; 47: 290-3.

104. Salomaa V, Riley W, Kark JD, et al. Non-insulin-dependent diabetes mellitus and fasting glucose and insulin concentrations are associated with arterial stiffness indexes. The ARIC Study. Circulation 1995; 91: 1432-43.

105. Hall JE. Pathophysiology of Obesity Hypertension. Curr Hypertens Rep 2000; 2 : 139-47.

106. Garrison RJ, Kannel WB, Stokes J III, et al. Incidence and precursors of hypertension in young adults: the Framingham Offspring Study. Prev Med 1987; 16 : 234-51.

107. Kumanyiaka S. Obesity in black women. Epidemil Rev 1987; 9: 31-50.

108. Torres MR, Barroso SG, Fagundes VG, et al. Effects of $10 \%$ weight loss on blood pressure and metabolic profile in obese adults. J Am Coll Cardiol 1998; 31(Suppl C): 433C.

109. Rocchini AP, Moorehead CP, DeRemer S, Bondie D. Pathogenesis of weight related changes in blood pressure in dogs. Hypertension 1989; 13: 922-8.

110. Hall JE, Brands MW, Henegar JR, Shek EW. Abnormal kidney function as cause and a consequence of obesity hypertension. Clin Experim Pharmacol Physiol 1998; 25: 58-64.

111. Hall JE. Mechanisms of abnormal renal sodium handling in obesity hypertension. Am J Hypertens 1997; 10: 49S-55S.

112. Kido K, Matsuura H, Otsuki T, et al. Sodium chloride sensitivity, intracellular sodium concentration in erythrocytes and lymphocytes, and renin profile in essential hypertension. Jpn Circ J 1989; 53: 101-7.

113. Porter LE, Hollenberg NK. Obesity, salt intake, and renal perfusion in healthy humans. Hypertension 1998; 32: 144-8.

114. Friedman SM. Salt sensitivity and cell permeability. J Hypert 1991; 9: 789-98.

115. Siffert W, Dussing R. Sodium-proton exchange and primary hypertension: an update. Hypertension 1995; 26: 649-55.

116. Barroso SG, Fagundes VGA, Sanjuliani AF, Francischetti EA. The possible associations of intracellular sodium and hemodynamic variables of the insulin resistance syndrome in a group of overweight multiethnic brazilian subjects. Trace Elem Electrolytes 2000; 17: 97-101.

117. Barroso SG, Flores EEI, Fagundes VGA, et al. Activity of membrane ATPases in overweight hypertensive patients: relationships to metabolic and hemodynamic variables. J Hypert 1999; 17 (S3): S51-S52.

118. Wofford MR, Adair C, Anderson DC, et al. Alpha and beta adrenergic blockade in obese and lean hypertensive subjects. Hypertension 1998; 32: 595-602.

119. Rocchini AP, Mao HZ, Babu K, et al. Clonidine prevents insulin resistance and hypertension in obese dogs. Hypertension 1999; 33: 548-53.

120. Kassab S, Kato T, Wilkins C, et al. Renal denervation attenuates the sodium retention and hypertension associated with obesity. Hypertension 19954; 25: 893-7.

121. Ward K, Sparrow D, Landsberg L, et al. Influence of insulin, sympathetic nervous system activity and obesity on BP: the Normative Aging Study. J Hypertens 1996; 14(3): 301-8.

122. Eisenhofer G, Esler MD, Goldstein DS, Kopin U. Neuronal uptake, metabolism, and release of tritium-labeled norepinephrine during assessment of its plasma kinetics. Am J Physiol 1991; 261: E505-E515.

123. Anderson EA, Sinkey CA, Lawton WJ, Mark AL. Elevated sympathetic nerve activity in bordeline hypertensive man: Evidence from direct intraneuronal recordings. Hypertension 1998; 14: 177-83.

124. Akselrod S, Gordon D, Madwed JB, et al. Hemodynamic regulation: investigation by spectral analysis. Am J Physiol 1985; 249: H867-H875.

125. Vaz M, Jennings G, Turner A, et al. Regional sympathetic nervous activity and oxygen consumption in obese normotensive human subjects. Circulation 1977; 6: 3423-9.

126. West D, Wehberg KE, Kieswetter K, Granger J. Blunted natriuretic response to an acute sodium load in obese hypertensive dogs. Hypertension 1992; 19(Suppl I): I196-I210.

127. Grassi G, Seravalle G, Cattaneo BM, et al. Sympathetic activation in obese normotensive subjects. Hypertension 1995; 25 (part I): 560-3

128. Gudbjornsdottir S, Lonroth P, Sverrisdottir YB, et al. Sympathetic nerve activity and insulin in obese normotensive and hypertensive men. Hypertension 1996; 27: 276-80.

129. Haynes WG, Morgan DA, Walsh SA, Mark AL, Sivitz WI. Receptor-mediated regional sympathetic nerve activation by leptin. J Clin Invest 1997; 100: 270-8.

130. Shek EW, Brands MW, Hall JE. Chronic leptin infusion increases arterial pressure. Hypertension 1998; 31 (part II): 409-14.

131. Frühbeck G. Pivotal role of nitric oxide in the control of blood pressure after leptin admnistration. Diabetes 1999; 48: 903-8.

132. Lombo G, Vecchione C, Fratta L, et al. Leptin induces direct vasodilation through distinct endothelial mechanisms. Diabetes 2000; 49: 293-7.

133. Shek EW, Kim PK, Hall JE. Adrenergic blockade prevents leptin-induced hyertension (abstract). Fed Proc 1999; 13: A456.

134. Caprio S, Tamborlane WV, Silver D, et al. Hyperleptinemia: an early sign of juvenile obesity. Relations to body fat depots and insulin concentrations. Am J Physiol 1996; 271: E626-E630.

135. Cigolini M, Seidell J, Targher G, et al. Fasting serum insulin in relation to components of the metabolic syndrome in European healthy men: the European Fat Distribution Study. Metabolism 1995; 44: 35-40.

136. Harris RBS. Leptin-much more than a satiety signal. Annu. Rev Nutr 2000; 20: 45-75.

137. Barroso SG, Genelhu-Fagundes V, Sanjuliani AF, et al. Association of leptin/ $\mathrm{BMI}^{22}$ with the metabolic syndrome independent of BMI in obese hypertensive patients. Am J Hypert 2001; 14(S1): A225.

138. Monroe MB, Van Pelt RE, Schiller BC, Seals DR, Jones PP. Relation of leptin and insulin to adiposity-associated elevations in sympathetic activity with age in humans. Int J Obes 2000; 24: 1183-7.

139. Reaven GM. Role of insulin resistance in human disease. Diabetes 1988; 37 : 1595-607.

140. Laws A, Reaven GM. The effect of physical activity on age-related glucose intolerance. Clin Geriatr Med 1990; 24: 495-503.

141. Laws A, Atefanick ML, Reaven GM. Insulin resistance and hypertriglyceridemia in first-degree relatives of patients with NIDDM. J Clin Endocrinol Metab 1989; 69: 343-7

142. Ferrannini E, Buzzigoli G, Bonadonna R. Insulin resistance in essential hypertension. N Engl J Med 1987; 317: 350-7.

143. Després JP, Marette A. Relation of components of insulin resistance syndrome to coronary disease risk. Curr Opin Lipidol 1994; 5: 274-89.

144. Garg A, Fleckentin JL, Peshock RM, Grundy SM. Peculiar distribution of adipose tissue in patients with congenital generalized lipodystrophy. J Clin Endocrinol Metab 1992; 75: 358-61.

145. Chandalia M, Garg A, Vuitch F, Nizzi F. Postmorten findings in congenital generalized lipodysthrophy. J Clin Endocrinol Metab 1995; 80: 3077-81.

146. Garg A. The role of body fat distribution in insulin resistance. In: Reaven GM, Laws A, ed. Insulin Resistance, The Metabolic Syndrome X. Humana Press, NJ, 1999, pp 83-96.

147. Laws A, Jeppesen JL, Maheus PC, Schaal P, Chen Y-Di, Reaven GM. Resistance to insulin - stimulated glucose uptake and dyslipidemia in Asian Indians. Arterioscl Thromb Vasc Biol 1994; 14: 917-22.

148. Jeppesen J, Hollenbeck CB, Zhou M-Y, et al. Relation between insulin resistance, hyperinsulinemia, posheparin plasma lipoprotein lipase activity and postprandial lipemia. Arterioscl Thromb Vasc Biol 1995; 15: 320-4.

149. Karpe F, Olivecroma T, Walldins G, Hamstem A. Lipoprotein lipase im plasma after an oral fat load. Relation to fre fatty acids. J Lipid Res 1992.33: 975-84.

150. Peterson J, Bihain BE, Bengtson-Olivecrona G, Deckelbaum RJ, Carpentier YA, Olivercrona T. Fatty acid control of lipoprotein lipase. A link between energy metabolism and lipid transport. Proc Nak Acad Sci USA 1990; 87: 909-13.

151. Saxena U, Witte LD, Goldberg IJ. Release of endotelial cell lipoprotein lipase by plasma lipoproteins and free fatty acids. J Biol Chem 1989; 264: 4349-55.

152. Karpe F, Hultin M. Endogenous triglyceride-rich lipoproteins accumulate in rat plasma when competing with a chylomicron-like triglyceride emulsion for a common lipolytic pathway. J Lipid Res 1995; 36: 1557-66.

153. Zilversmit DB. Atherogenesis: A postprandial phenomenon. Circulation 1979; 60: 473-85.

154. Fricker J, Fumeron F, Clair D, Apfelbaum M. A positive correlation between energy intake and body mass index in population of 1312 overweight subjects. Int $\mathrm{J}$ Obesity 1989; 13: 663-81.

155. Ronst LR, Jensen MD. Postprandial free fatty acid kinetics are abnormal in upper body obesity. Diabetes 1993: 42: 1567-73.

156. Morton RE, Zilversmit DB. Inter-relationship of lipids transferred by the lipidtransfer protein isolated from human lipoprotein-deficient plasma. J Biol Chem 1989; 258: 11751-7. 
157. Lagrost L, Florentin E, Guyard-Dangremont V, et al. Evidence for nonesterified fatty acids as modulators of neutral lipid in normolipidemic human plasma. Arterioscl Tnromb Vasc Biol 1995; 15: 1388-96.

158. Patsch JR, Prasad S, Gotto AM, Bengtsson-Olivecrona G. Postprandial lipdemia: A key for the conversion of high density lipoprotein 2 into high density lipoprotein 3 by hepatic lipase. J Clin Invest 1984; 74: 2017-23.

159. Griffin BA, Freeman DJ, Tait GW, et al. Role of plasma triglyceride in the regulation of plasma low density lipoprotein (LDL) subfractions: relative contribution of small, dense LDL to coronary heart disease risk. Atherosclerosis 1994; 106: 241-53

160. Karpe R, Tornval P, Olivecrona T, Steiner G, Carlson LA, Hamsten A. Composition of human low density lipoprotein: effects of postprondial triglyceride-rich lipoproteins, lipoprotein lipase, hepatic lipase and cholesteryl ester transfer protein. Atherosclerosis 1993; 98: 33-49.

161. Laws A. Insulin resistance and dyslipidemia: Implications for coronary heart disease risk. In Reaven GM, Laws A, ed. Insulin Resistance, The Metabolic Syndrome X. Humana Press, NJ, 1999,pp 267-80.

162. Després JP, Nadeau A, Tremblay A, Ferland M, Lupien PJ. Role of deep abdominal fat in the association between regional adipose tissue distribution and glucose tolerance in obese women. Diabetes 1989; 38: 304-9.

163. Pouilot MC, Després JP, Nadeau A, et al. Associations with tolerance plasma insulin, and lipoprotein levels. Diabetes 1992; 41: 826-34.
164. Després JP, Lemieux S, Lamarche B, et al. The insulin-resistance syndrome: Contribution of visceral obesity and therapeutic implications. Int J Obes 1995; 19(suppl): S76-S86.

165. Tchernof A, Lamarche B, Prud'homme D, et al. The dense LDL phenotype: association with plasma lipoprotein levels, visceral obesity, and hyperinsulinemia. Diabetes Care 1996; 19(6): 629-37.

166. Després JP, Lamarche B, Mauriège P, et al. Hyperinsulinemia as an independent risk factor for ischemic heart disease. N Engl J Med 1996; 334: 952-7.

167. Lamarche B, Tchernog A, Moorjani S. Small, dense low density lipoprotein particles as perdictors of the risk of ischemic heart disease in men: prospective results from the Québec Cardiovascular Study. Circulation 1997; 95: 69-75.

168. Després JP, Marette A. Obesity and Insulin Resistance. Epidemiologic, Metabolic, and Molecular Aspects. In: Insulin Resistance, The Metabolic Syndrome X, Reaven GM, Laws A eds New Jersey: Humana Press 1999; pp51-81.

169. Gaudet D, Vohl MC, Perron P, et al. Relationships of abdominal obesity and hyperinsulinemia to angiographically assessed coronary artery disease in men with known mutations in the LDL-receptor gene. Circulation 1998; 97: 871-7.

170. Ronnemaa T, Marniemi J, Sarolainen MJ, et al. Serum lipids, lipoproteins, and lipid mebolizing enzymes in identical twins discordant for obesity. JClin Endocrinol Metabol 1998; 83: 2792-9.

\section{Mevalotin (pravastatina) - Informações para prescrição (resumidas)}

Contra-indicações: Pacientes com hipersensibilidade a qualquer componente da fórmula; Distúrbio hepático ativo ou elevações persistentes, não explicadas, nos testes de função hepática; Gravidez ou lactação. Descontinuar a terapia com a pravastatina caso ocorra gravidez. Precauções: Deverão ser realizados testes de função hepática periodicamente, pois os inibidores da HMG-CoA redutase foram associados com alterações bioquímicas da função hepática. Caso ocorra aumento persistente das transaminases (ALT e AST) igual ou superior em três vezes o limite superior normal, a terapia deverá ser descontinuada. Em pacientes com histórico de doença hepática ou de grande ingestão alcoólica recomenda-se monitorização mais intensa quando a pravastatina for administrada. Musculatura Esquelética: Mialgia, miopatia e rabdomiólise foram relatados com o uso de inibidores da HMG-CoA redutase. Casos de mialgia não-complicada foram raramente relatados em pacientes tratados com a pravastatina, com uma incidência similar à do placebo. Rabdomiólise com disfunção renal secundária à mioglobinúria também tem sido relatada devido à pravastatina, embora muito raramente. Pacientes deverão ser alertados para relatar imediatamente dor, amolecimento ou enfraquecimento musculares inexplicáveis. A terapia com a pravastatina deverá ser descontinuada se ocorrerem aumentos acentuados dos níveis de CPK ou se houver suspeita ou diagnóstico de miopatia (definida como dor ou fraqueza muscular associada a aumento nos valores de creatinofosfoquinase $-\mathrm{CPK}$ - acima de 10 vezes o limite superior normal). O risco de miopatia durante o tratamento com outros inibidores da HMG-CoA redutase é maior com a terapia concomitante com fibratos, ciclosporina, eritromicina ou niacina. Em um estudo clínico de tamanho limitado, não foi relatada miopatia com a terapia combinada pravastatina (40mg/dia) e genfibrozil (1200 mg/dia), embora tenha sido observada tendência para elevações de CPK e sintomas musculoesqueléticos. Contudo, o uso combinado de pravastatina e fibratos deverá ser evitado. Não foi observada a ocorrência de miopatia nos estudos clínicos com 100 pacientes pós-transplantados (24 renais e 76 cardíacos) tratados concomitantemente com pravastatina $(10-40 \mathrm{mg})$ e ciclosporina por até 2 anos, sendo que alguns foram submetidos também à terapia com outros imunodepressores. Além disso não houve relatos de miopatia nos estudos clínicos envolvendo pequeno número de pacientes tratados com a pravastatina juntamente com a niacina. Hipercolesterolemia Homozigótica Familiar: A pravastatina não foi avaliada em pacientes com hipercolesterolemia homozigótica familiar de incidência rara. Lactação: Mães em terapia com Mevalotin (pravastatina) não deverão amamentar. Uso Pediátrico: A segurança e efetividade em crianças e adolescentes, com menos de 18 anos de idade, não foi estabelecida. Portanto, o tratamento com Mevalotin (pravastatina) não pode ser recomendado para este grupo etário. Interações Medicamentosas: Colestiramina /Colestipol: Não houve diminuição clinicamente significante da biodisponibilidade ou do efeito terapêutico quando a pravastatina foi administrada uma hora antes ou quatro após a colestiramina ou uma hora antes do colestipol e uma refeição normal. A administração concomitante resultou em redução de $40 \%$ a $50 \%$ da AUC média da pravastatina. Ciclosporina: Níveis plasmáticos da ciclosporina em pacientes sob tratamento com pravastatina, não indicam aumentos clinicamente significativos nestes valores. Em estudo de dose única, os níveis plasmáticos da pravastatina estavam aumentados em pacientes cardíacos transplantados recebendo ciclosporina. Varfarina: A pravastatina não teve efeito clinicamente significante sobre o tempo de protrombina quando administrada em um estudo de pacientes idosos normais que foram estabilizados com a varfarina. Outros fármacos: Uma terapia de associação com um ou mais agentes complementares redutores de lipídios pode ser necessária em alguns pacientes. Ao contrário da maioria dos inibidores da HMG-CoA redutase, a pravastatina não é significantemente metabolizada pelo citocromo P450 3A4. Estudo de interação farmacocinética com ácido acetilsalicílico, antiácidos (uma hora antes de Mevalotin), ácido nicotínico, probucol, gemfibrozil e cimetidina não demonstraram alteração na biodisponibilidade com a administração de Mevalotin (pravastatina). Nos pacientes tratados simultaneamente com resinas fixadoras de ácidos biliares, Mevalotin(pravastatina) deve ser administrado 1 ou mais horas antes, ou 4 horas após uma dose de resina. O clearence de antipirina pelo sistema citocromo P450 permaneceu inalterado pela administração de Mevalotin (pravastatina). Durante ensaios clínicos não foram relatadas interações medicamentosas perceptíveis quando Mevalotin (pravastatina) foi administrado com diuréticos, anti-hipertensivos, digitálicos, inibidores da enzima conversora, bloqueadores dos canais de cálcio, betabloqueadores ou nitroglicerina. Reações adversas: Em dois estudos controlados com placebo, o perfil de segurança e tolerabilidade no grupo da pravastatina foi comparável ao do grupo placebo em mais de 10.754 pacientes tratados por mais de 4,8 - 5,9 anos (média). Os seguintes eventos adversos foram relatados por mais de $2 \%$ dos pacientes de estudos controlados com placebo de até 4 meses de duração, independentemente da etiologia: Musculatura esquelética: Dor musculoesquelética localizada, mialgia; Gastrintestinais: Náuseas/ vômitos, diarréia, constipação, dor abdominal, flatulência; Respiratórias: resfriado comum, rinite; Neurológicas: Cefaléia, vertigem; Gerais: Fadiga, dor no peito (não cardíaca); Dermatológicas: Erupção cutânea; Cardiovasculares: Dor no peito. Cristalino: Durante o tratamento por períodos de um ano ou mais, 820 pacientes tratados com pravastatina não revelaram evidências relativas ao aparecimento de catarata. Posologia: O paciente deverá ser submetido a uma dieta redutora de colesterol antes de iniciar a terapia com Mevalotin (pravastatina), que deverá ser mantida durante o período de tratamento. A dose recomendada é $10 \mathrm{mg}$ a $40 \mathrm{mg}$ uma vez ao dia, independente das refeições, de preferência à noite (pois parece ser ligeiramente mais efetiva do que a dose única pela manhã). A posologia diária também pode ser administrada em doses divididas. Superdosagem: A experiência sobre a superdosagem de pravastatina é limitada. Até o momento, há relato de dois casos, que foram assintomáticos e não associados a anormalidades em testes clínicos laboratoriais. Pacientes idosos: O produto poderá ser usado por pacientes acima de 65 anos de idade, desde que observadas as precauções comuns ao medicamento.

Registro no MS n. 1.0454.0047 